\title{
Mechanistic Approach to Thermal Production of New Materials from Asphaltenes of Castilla Crude Oil
}

\author{
Natalia Afanasjeva ${ }^{1}$, Andrea González-Córdoba ${ }^{2, *} \mathbb{C}$ and Manuel Palencia ${ }^{1}$ \\ 1 Department of Chemistry, Faculty of Natural and Exact Science, Universidad del Valle, \\ Cali 760020, Colombia; natalia.afanasjeva@correounivalle.edu.co (N.A.); \\ manuel.palencia@correounivalle.edu.co (M.P.) \\ 2 Department of Chemical and Environmental Engineering, Faculty of Engineering, Universidad Nacional \\ de Colombia, Bogotá 111321, Colombia \\ * Correspondence: angonzalezc@unal.edu.co; Tel.: +57-1-316-5000 (ext. 14322)
}

Received: 16 August 2020; Accepted: 23 October 2020; Published: 12 December 2020

\begin{abstract}
Asphaltenes are compounds present in crude oils that influence their rheology, raising problems related to the extraction, transport, and refining. This work centered on the chemical and structural changes of the asphaltenes from the heavy Colombian Castilla crude oil during pyrolysis between 330 and $450{ }^{\circ} \mathrm{C}$. Also, the development of new strategies to apply these macromolecules, and the possible use of the cracking products as a source of new materials were analyzed. The obtained products (coke, liquid, and gas) were collected and evaluated through the techniques of proton and carbon-13 nuclear magnetic resonance $\left({ }^{1} \mathrm{H}\right.$ and $\left.{ }^{13} \mathrm{C} \mathrm{NMR}\right)$, elemental composition, Fourier-transform infrared spectroscopy (FTIR), X-ray powder diffraction (XRD), saturates, aromatics, resins, and asphaltenes (SARA) analysis, and gas chromatography-mass spectrometry (GC-MS). A comparison of the applied methods showed that the asphaltene molecules increased the average size of their aromatic sheets, lost their aliphatic chains, condensed their aromatic groups, and increased their degree of unsaturation during pyrolysis. In the liquid products were identified alkylbenzenes, n-alkanes $\mathrm{C}_{9}-\mathrm{C}_{30}$, and n-alkenes. Moreover, the gaseous products included methane, ethane, propane, and pentane. An approach of the structural chain reaction was used to define the possible asphaltenes chemical structures before and after pyrolysis. In conclusion, this type of thermal process can be used as an easy route to attain new materials associated with specific structural units from the asphaltenes.
\end{abstract}

Keywords: pyrolysis; asphaltenes; chain reaction; structural parameters

\section{Introduction}

Asphaltenes are compounds present in heavy crude oil as a complex mixture of amorphous solids, containing $\mathrm{C}, \mathrm{H}, \mathrm{N}, \mathrm{O}$, and $\mathrm{S}$ as the main components in the aromatic core and various trace metals, mainly Ni and V, as porphyrins [1]. Structurally, asphaltenes consist mainly of condensed aromatic rings with short aliphatic chains. So, they are a mixture of non-linear macromolecules with high polydispersity [2-4]. The classical definition of asphaltenes is based on their solubility, but this criterion is chemically limited. Moreover, it has been demonstrated that the asphaltenes fractions elemental composition, precipitated using different solvents, significantly depends on their origin [5].

Diverse approaches have been proposed to define an "average structure" for asphaltenes. The archipelago model [6] described asphaltene units as a sequence of molecules stacked in parallel planes and forming a cluster of four to five layers of naphthene-aromatic hydrocarbons. Further, they present planarity deviations and steric hindrance. This model has been supported by nuclear magnetic resonance (NMR), Fourier-transform ion cyclotron resonance mass spectrometry (FT-ICR MS/MS), and thermal cracking methods [7]. Subsequently, the island model [5] explained that 
asphaltenes are a set of single aromatic hydrocarbons. They contain cycloalkanes, branched-chain substituents, heteroatoms such as nitrogen, in pyrrole and pyridine-like structures, and sulfur atoms in the thiophene-like units. The oxygen atom is mainly related to phenolic compounds or ethers of aliphatic substituents. Metals $\mathrm{V}$ and $\mathrm{Ni}$ are associated with porphyrins in much smaller amounts. Li \& Greenfield [8] recommended retaining the overall architecture, whereas the location of several side groups was changed to restore the planarity of the aromatic rings. Recently, new findings [9] support the idea of a macromolecule consistent with the existence of both kinds of models. The ratios of the archipelago and island structures depended on the asphaltene origin [7].

The archipelago model is mainly obtained using X-ray diffraction (XRD). It is a non-destructive technique that has been established to evaluate the carbon stacking structure in carbon materials, such as asphaltenes. Quantitative analyses are calculated by the peak intensity and position [7]. Thus, four peaks constitute the XRD pattern and correspond to the $\gamma,(002)$, (10), and (11) bands. Among them, aliphatic interchain distance is identified through the $\gamma$-band, and aromatic interlayer distance is evaluated using the (002) band. A curve-resolving software can be effectively applied to resolve the different signals from the diffractogram and determine its baseline [10].

Considering the limitations and benefits of XRD, some researchers $[1,11]$ have combined this method with other advanced techniques to improve the quality of the structural information. For example, Hemmati-Sarapardeh et al. [11] selected three types of asphaltenes and characterized them by elemental analysis, XRD, and Fourier-transform infrared spectroscopy (FTIR). Using these methods, they investigated the composition, functional groups, and structural parameters from the asphaltenes and the effects over their colloidal behavior in normal alkane-toluene mixtures. Moreover, other analytical techniques, such as nuclear magnetic resonance (NMR) and gel permeation chromatography (GPC), have been used together to evaluate asphaltene parameters and structures. Thus, ${ }^{1} \mathrm{H}$ and ${ }^{13} \mathrm{C}$ NMR with elemental analysis and GPC data provided quantitative information related to the different kinds of protons and carbon in asphaltenes [12]. The proposed model structures are useful to identify their changes during transformation processes, such as pyrolysis, thermal cracking, and catalytic hydrogenation [1]. Also, XRD, along with techniques as GPC, UV spectrophotometry, Raman spectroscopy, and elemental analysis, have been used to investigate the changes of asphaltene molecules under different thermal treatments. In this way, some researchers found that thermal cracking raised the aromaticity, but reduced the molecular weight and average diameter of the aromatic sheets, at the same time losing the aliphatic chains. Interchain distance, interlayer distance, and the diameter of the aromatic clusters did not significantly change when the severity of cracking increased. Additionally, they identified that the stack diameter was not affected by the fractionation of asphaltenes [7].

Despite the average structure concept, the asphaltenes are a complex mixture. Their use might be acceptable in the oil industry, but their direct application in other fields could be considered inappropriate. For instance, reproducible characteristics of resulting products are one of the most desired qualities for the development of new materials. Thus, the isotropy and homogeneity of properties are necessary to manufacture more sophisticated products, such as paints, coating technologies, or structural materials. According to this, asphaltenes are not expected as an ideal source to produce new materials without previous processes of separation or transformation.

Aspects as their structural diversity, high viscosity, and high heterogeneity of properties make difficult the separation of asphaltene components and the direct implementation of this strategy for features related to design, characterization, modeling, and scaling [2-6]. Asphaltene transformation can be easily performed by pyrolysis. It is a thermal technique that appears to be an alternative way to obtain smaller molecules from macromolecule complex mixtures. Pyrolysis allows the transformation of the asphaltene mixture into a mix of raw materials with lower complexity and easing the separation stages. However, it is necessary to understand the chemical and structural transformation of asphaltenes during pyrolysis for better control of this strategy. Thus, the objective of this work was to study the chemical and structural conversion of asphaltenes during pyrolysis between 330 and $450{ }^{\circ} \mathrm{C}$, in order 
to develop new strategies to use these macromolecules and their pyrolytic by-products as a source of new materials.

\section{Materials and Methods}

\subsection{Materials}

Asphaltenes sample was isolated from the Colombian heavy crude oil of the Castilla field supplied by Ecopetrol S.A (9.6 API, asphaltene content of 20.8\%). The American Society for Testing and Materials (ASTM) D6560-17 standard method was followed to extract the asphaltenes. Briefly, the saturates, aromatics, resins, and asphaltenes (SARA) fraction being soluble in toluene was precipitated with n-heptane (ratio $30 \mathrm{~mL}: 1 \mathrm{~g}$ ) from the crude oil. The purification of the asphaltenes was performed using the Soxhlet method with toluene reflux at $90-95^{\circ} \mathrm{C}$ for $12 \mathrm{~h}$. The soluble fraction was recovered as asphaltenes, while the insoluble fraction of the resins was removed. Samples were dried, milled, sieved for obtaining a particle size lower than 0.2 mesh, and used in all the subsequent experiments. All the solvents used were analytical grade (J.T. Baker, Steinheim, Germany). Table 1 shows the main physicochemical properties of the asphaltenes from Castilla crude oil.

Table 1. Physicochemical characterization of the asphaltenes from Castilla crude oil.

\begin{tabular}{ccc}
\hline Parameter & Standard Method & Value \\
\hline Humidity (wt \%) & American Society for Testing and Materials (ASTM) D5142-09 & $1.76 \pm 0.01$ \\
Volatile matter (wt \%) & ASTM D5142-09 & $57.29 \pm 0.01$ \\
Ash (wt \%) & ASTM D5142-09 & $0.59 \pm 0.01$ \\
Fixed carbon $(w t \%)$ & ASTM D3172-13 & $40.36 \pm 0.01$ \\
Nickel (mg/kg) & ASTM D5863-00a & $382 \pm 1$ \\
Vanadium (mg/kg) & ASTM D5863-00a & $1851 \pm 1$ \\
Average molecular weight $(\mathrm{g} / \mathrm{mol})$ & ASTM D5296-19 & $1492 \pm 206$ \\
Polydispersity index, Mw/Mn & ASTM D5296-19 & $3.8 \pm 0.3$ \\
\hline
\end{tabular}

\subsection{Determination of the Molecular Weight of the Asphaltenes}

The average molecular weight (MW) and polydispersity index of the asphaltenes were tested following the D5296-19 standard method. A gel permeation chromatography system (GPC, Shimadzu Scientific Instruments, Columbia, MD, USA), equipped with a RI detector, was used in all the measurements. The runs were performed at $30{ }^{\circ} \mathrm{C}$ with a column $(10 \mu \mathrm{m}$ Mixed-B PLgel, Hewlett-Packard) and a pre-column (PLgel Guard Column), maintaining a constant flow rate $(0.5 \mathrm{~mL} / \mathrm{min})$. The calibration was made using low-dispersion polystyrene standards with molecular weights of 20,650, 7000, 2100, and 580 g/mol (Polymer Laboratories Ltda., Church Stretton, UK). The asphaltene samples were dissolved in tetrahydrofuran ( $0.08 \mathrm{~g}$ asphaltenes $/ 1 \mathrm{~L}$ solvent). All the measurements were carried out in duplicate.

\subsection{NMR Analysis of Asphaltene Structure}

The asphaltenes were characterized through ${ }^{1} \mathrm{H}$ and ${ }^{13} \mathrm{C}$ NMR using a Bruker 400 UltraShield ${ }^{\mathrm{TM}}$ NMR spectrometer. Deuterated chloroform $\left(\mathrm{CDCl}_{3}\right)$ (Sigma-Aldrich, St. Louis, MO, USA) was used as the solvent $\left(20 \mathrm{mg}\right.$ of asphaltene sample per $600 \mu \mathrm{L}$ of $\mathrm{CDCl}_{3}$ ), and chromium (III) acetylacetonate $\left(\mathrm{Cr}(\mathrm{AcAc})_{3}\right)$ (Sigma-Aldrich, St. Louis, MO, USA) was applied as a relaxing agent (12 $\mathrm{mg}$ of $\mathrm{Cr}(\mathrm{AcAc})_{3}$ per $150 \mathrm{mg}$ of asphaltene). Spectra were recorded using $300.13 \mathrm{MHz}$ for ${ }^{1} \mathrm{H}$ NMR and $75.47 \mathrm{MHz}$ for ${ }^{13} \mathrm{C}$ NMR. The chemical shift scale in the ${ }^{1} \mathrm{H}$ and ${ }^{13} \mathrm{C}$ NMR spectra was calibrated using the residual non-deuterated $\mathrm{CHCl}_{3}$ signal at 7.24 and $77.16 \mathrm{ppm}$, respectively. The ${ }^{1} \mathrm{H} \mathrm{NMR}$ data were recorded in a range between 10 and 0 ppm, and the ${ }^{13} \mathrm{C}$ NMR spectrum was measured between 180 and $-10 \mathrm{ppm}$. For analysis, spectra were divided into regions of aliphatic and aromatic compound signals [13]. Also, aliphatic protons were divided into three types $\left(\mathrm{H}_{\alpha}, \mathrm{H}_{\beta}\right.$, and $\left.\mathrm{H}_{\gamma}\right)$, according to their position regarding the aromatic nucleus of the asphaltenes. By this method, the experimental error 
in the ${ }^{1} \mathrm{H}$ NMR results is approximately $2 \%$ [12,14]. The methods proposed by Dickinson [15] and Speight [16] were adopted to interpret the ${ }^{1} \mathrm{H}$ NMR spectrum and analyze the band area. The average structural parameters determined for asphaltenes were: the sum of the aromatic hydrogens $(A r-H)$, the sum of aliphatic hydrogens $(A l-H)$, the number of aromatic carbons $(A r-C)$, the number of aliphatic carbons $(A l-C)$, the average number of carbons of the hydrocarbon chain $(n)$, the aromaticity factor $(A)$, the substitution percentage of aromatic rings $\left(A r_{s u s}\right)$ for unbonded carbon atoms, the number of internal aromatic carbons $\left(C_{i n}\right)$, the ratio of aliphatic chains per aromatic hexagon and the aromatic size $(p-C / A r-C)$, where $p-C$ represents the amount of the aromatic peripheral carbons. The $p-C$ value was corrected according to Ancheyta et al. [17] and Savage et al. [18].

\subsection{Thermal Analysis of Asphaltenes}

Differential scanning calorimetry-thermogravimetric analysis (model: TA Instruments equipment, simultaneous DSC-TGA, SDT Q600, New Castle, DE, USA) was developed to define the range of experimental temperatures. A nitrogen atmosphere was used at flow rates of $100 \mathrm{~mL} / \mathrm{min}$. Each asphaltene sample $(5.0 \pm 0.1 \mathrm{mg})$ was held in a $70 \mu \mathrm{L}$ alumina crucible for the experiment. The experimental temperature ranged from 25 to $100{ }^{\circ} \mathrm{C}$, and the heating rate was controlled at 10,15 , and $20^{\circ} \mathrm{C} / \mathrm{min}$.

\subsection{Pyrolysis of Asphaltenes}

Considering the TGA/DTA results, the pyrolysis was carried out between $330-450{ }^{\circ} \mathrm{C}$ using a reactor batch. More precisely, pyrolysis reactions were carried out in a $270 \mathrm{~mL}$ stainless steel batch type reactor (Figure 1). Briefly, a Pyrex glass containing $7 \mathrm{~g}$ of asphaltene was loaded into the reactor. Then, the reactor was purged several times with high-pressure $\mathrm{N}_{2}$ to provide an inert environment. The reaction proceeded under non-isothermal conditions from $25{ }^{\circ} \mathrm{C}$ to the pyrolysis temperature $\left(330,360,390,420\right.$, and $\left.450{ }^{\circ} \mathrm{C}\right)$ at a heating rate of $5^{\circ} \mathrm{C} / \mathrm{min}$. The reaction stopped immediately after reaching the pyrolysis temperature by removing the reactor from the external electric heater and plunging it in a cold-water bath to quench the reaction. The reactor content was collected as unreacted asphaltenes, coke, liquid, and non-condensable gaseous products. The yield of the solid and liquid fractions was determined gravimetrically. The material balance was made to calculate the quantity of non-condensable gases. Gaseous and liquid products were taken in sealed probes directly connected to the reactor, and they were tested immediately after the pyrolysis. After pyrolysis, the solid fraction inside the reactor was extracted with toluene recirculation in a Soxhlet apparatus for $12 \mathrm{~h}$. The soluble fraction was recovered as asphaltenes and the insoluble fraction as coke. All the liquid and solid samples were conserved in amber glass flasks at low temperatures in a desiccator.

\subsection{Chemical Composition}

The pyrolysis is an important thermal cracking method, and it generates three types of products, which are gases, oils, and coke. The CHNS elemental analysis of the asphaltene samples, and the solid and liquid products from their pyrolysis was performed in triplicate using an elemental analyzer Thermo Finnigan Flash Model EA 1112. The ASTM D5373-16 standard method was followed to determine the C, H, and N content, and the ASTM D4239-18e1 standard method was carried out to determine the $\mathrm{S}$ content. The experimental error was $<2.0 \%$ and was determined from experimental data. The oxygen-atoms concentration was deduced of the weight percent of CHNS from 100 . Also, the calorific value of the original and pyrolyzed asphaltenes was estimated based on their elemental composition, using the Dulong equation [19]. 


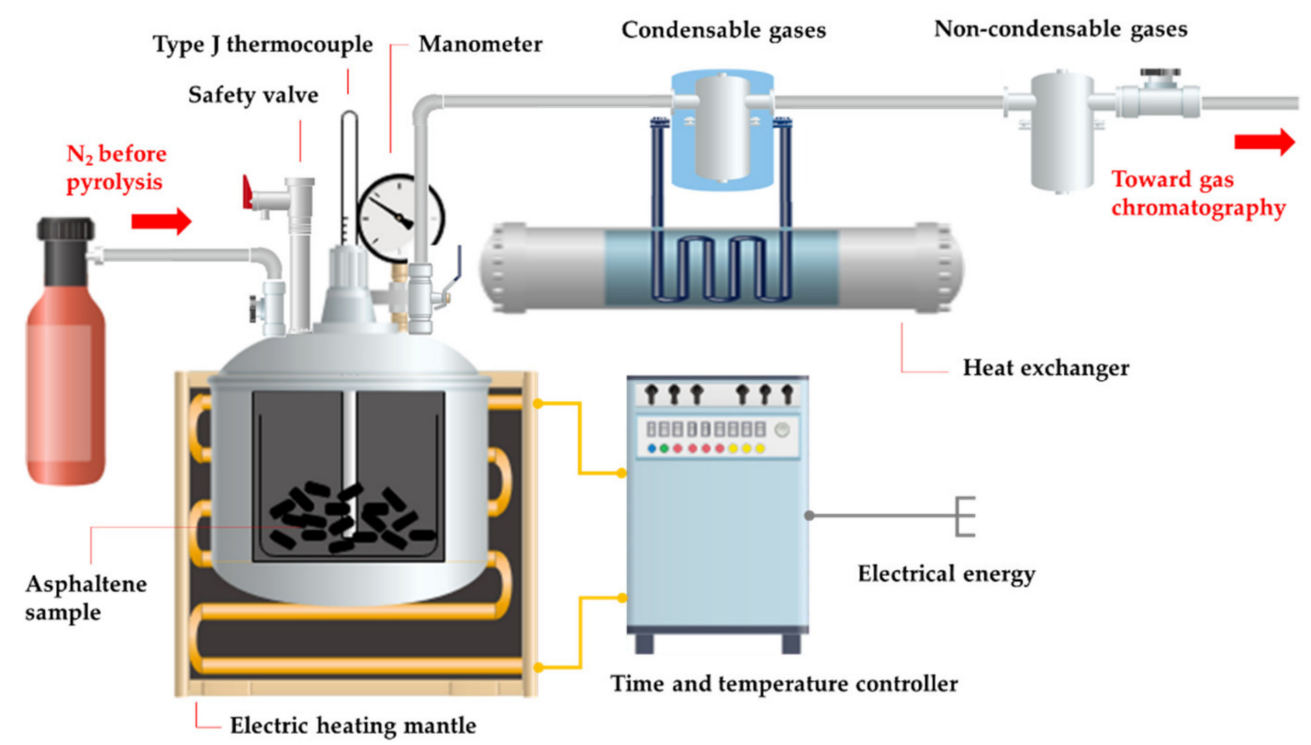

Figure 1. Scheme of the batch pyrolysis equipment.

\subsection{FTIR Analysis}

FTIR analysis of the original and pyrolyzed asphaltenes was carried out using a Thermo Nicolet 870 spectrometer. This analysis was performed by transmission technique using KBr (Sigma-Aldrich, Gillingham, Dorset, UK) as a solid diluent to prepare pellets of the asphaltene samples. Spectra were recorded from 4000 to $400 \mathrm{~cm}^{-1}$ with a resolution of $4 \mathrm{~cm}^{-1}$ and 100 scans using a deuterated triglycine sulfate detector (Thermo Fisher Scientific, Waltham, MA, USA). Equations used to calculate asphaltenes structural relationships from the bands of the IR spectra are detailed in some references $[6,13,14,20]$. They include the relative aromaticity $(R A)$, degree of aromatic condensation $(A C D)$, degree of disubstitution $(D D)$, degree of aromatic substitution $(A S D)$, and ramification degree $(R D)$. The equations used to calculate asphaltenes structural relationships from the bands of the IR spectra are:

Relative aromaticity $(R A)$ is calculated from:

$$
R A=\frac{v(\mathrm{C}=\mathrm{C})}{v\left(\mathrm{CH}_{3}+\mathrm{CH}_{2}\right)}
$$

where $v(\mathrm{C}=\mathrm{C})$ is the vibration band of aromatic carbons, and $v \mathrm{CH}_{3}+\mathrm{CH}_{2}$ is the asymmetric vibration band of $\mathrm{CH}_{3}$ and $\mathrm{CH}_{2}$ links.

Degree of aromatic condensation $(A C D)$ denotes aromatic rings penta-substituted related to hydrogen in aromatic carbons:

$$
A C D=\frac{\gamma_{\mathrm{CH}-\mathrm{AR} 2,3}}{\gamma_{\mathrm{CH}-\mathrm{AR} 1}}
$$

where $\gamma_{C H-A R} 2,3$ is the in-plane bending vibration band from two or three $\mathrm{C}-\mathrm{H}$ groups, and $\gamma_{\mathrm{CH}-A R 1}$ is the in-plane bending band from a C-H aromatic link.

Degree of disubstitution $(D D)$, and degree of aromatic substitution $(A S D)$ :

$$
\begin{gathered}
D D=\frac{\gamma_{\mathrm{CH}-\mathrm{AR} 4}}{\gamma_{\mathrm{CH}-\mathrm{AR} 1}} \\
A S D=\frac{A C D}{D D}
\end{gathered}
$$

Ramification degree $(R D)$ is calculated:

$$
R D=\frac{\delta_{\mathrm{CH}_{3}}}{\delta_{\mathrm{CH}_{3}+\mathrm{CH}_{2}}}
$$


where $\delta_{\mathrm{CH} 3}$ is the out-of-plane bending or deformation symmetric vibration band of methyl groups, and $\delta_{\mathrm{CH} 3+\mathrm{CH} 2}$ is the bending band asymmetric of methyl-methylene groups.

\subsection{X-ray Diffraction}

X-ray powder diffraction was developed with an equipment X'Pert PRO (Malvern PANalytical, Almelo, Netherlands). The diffraction patterns of the original and pyrolyzed asphaltenes were recorded at room temperature using a Co K $\alpha$ source $(\mathrm{k}=1.7890 \AA)$ at a scanning speed of 1 min with a step of $0.02 \theta(2 \mathrm{~h})$. The patterns obtained were smoothed before determining the position of the peaks, the intensity, the area, the interplanar distance, and the full width at half maximum (FWHM). The calculation of the structural parameters was performed according to Yen et al. [6], including the aromaticity factor $(f A)$, interchain distance $(d m)$, interlayer distance $(d \gamma)$, the diameter of the aromatic clusters $(L c)$, the effective number of associated aromatic layers in the cluster $(M e)$, the average diameter of the aromatic sheets $(L a)$, and weight of the aromatic sheet $(W A D)$.

\subsection{Elemental and SARA Analysis of the Liquid Product}

The composition of the liquid product was determined by elemental analysis. Additionally, the analysis of saturate, naphthene aromatics, and polar aromatics fractions (SARA) was carried out following the ASTM D4124-09 standard method.

\subsection{Gas Chromatography-Mass Spectrometry}

Liquid and gaseous products were characterized by GC coupled to MS using a GC-MS QP2010 Shimadzu equipment (Shimadzu, Kyoto, Japan). A GC non-polar and low-bleed column DB-1 (Agilent $\mathrm{J} \& \mathrm{~W})$ were used $(30 \mathrm{~m} \times 0.35 \mathrm{~mm}$ id, $0.32 \mu \mathrm{m}$ film thickness). The temperature was programmed at $70{ }^{\circ} \mathrm{C}(1 \mathrm{~min})$ and then heated to $310{ }^{\circ} \mathrm{C}$ at $6{ }^{\circ} \mathrm{C} / \mathrm{min}$ (with a retention time of $20 \mathrm{~min}$ ). The operating conditions of the MS equipment were the following: ionic source $240{ }^{\circ} \mathrm{C}$, total scanning with a mass range of 15-910 amu, and analysis time of $60 \mathrm{~min}$. The pyrolytic reactor was coupled in line with the GC-MS equipment to carry out the analysis of gaseous fraction.

\section{Results and Discussion}

\subsection{NMR Analysis of Asphaltene Structure}

The ${ }^{1} \mathrm{H}$ and ${ }^{13} \mathrm{C}$ NMR asphaltenes spectra (Figure 2) were used to calculate their average molecular parameters (Table 2). Among them, the value of the aromaticity factor was 0.4. The length of the aliphatic lateral chain was 4.0. The $p-C / A r-C$ ratio (0.73) refers to the number of aromatic carbons connected to other aromatic hexagons. So, it was associated with the size of the aromatic core and the average number of aromatic rings per molecule. According to this parameter, the number of peripheral carbons was 26, and the number of internal aromatic carbons was ten, since the values for $A r-C$ and Al-C were $40 \%$ and $60 \%$, respectively.

\subsection{Thermal Analysis of Asphaltenes}

DSC curves at different heating rates (Figure 3a) showed an endothermic peak before $100{ }^{\circ} \mathrm{C}$ due to the evaporation of the more volatile components. A glass transition temperature $\left(180-300{ }^{\circ} \mathrm{C}\right)$, characterized by a sudden change in the specific heat capacity, was also identified through a slight variation in the baseline (a turning point). This range was congruent with the glass transition temperatures for asphaltenes $\left(186-307^{\circ} \mathrm{C}\right)$ found by Yasar et al. [21]. Another endothermal peak was observed between $420-500{ }^{\circ} \mathrm{C}$, which was within the interval corresponding to pyrolysis. At temperatures above $650^{\circ} \mathrm{C}$, the decomposition of the solid samples continued. 


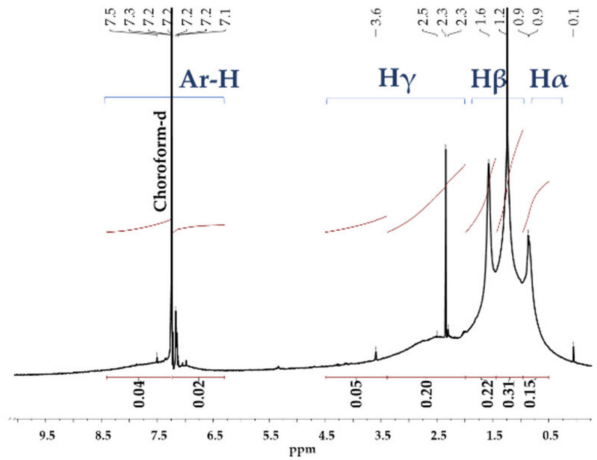

(a)

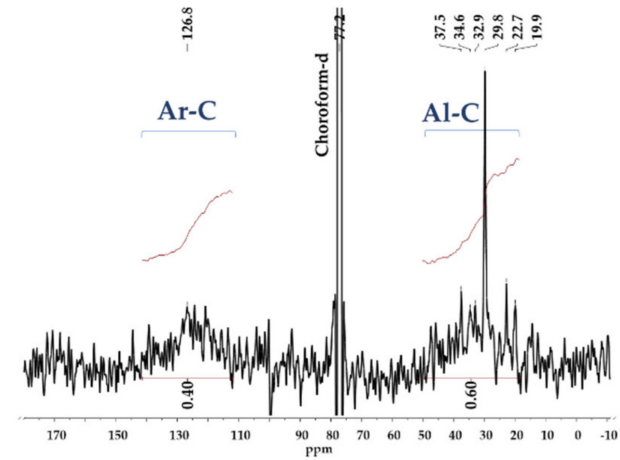

(b)

Figure 2. (a) ${ }^{1} \mathrm{H}$ NMR; (b) ${ }^{13} \mathrm{C}$ NMR asphaltenes spectra.

Table 2. Average molecular parameters of ${ }^{1} \mathrm{H}$ and ${ }^{13} \mathrm{C}$ NMR of the asphaltenes of Castilla crude oil.

\begin{tabular}{ccc}
\hline Sample Value (\%) & Domain (ppm) & Original Asphaltenes \\
\hline Aromatic proton, Ar-H (\%) & $6.30-9.30$ & 6 \\
Aliphatic proton, Al-H (\%) & $0.50-4.50$ & 94 \\
Aliphatic proton linked to a $\alpha$ carbon, $\mathrm{H}_{\alpha}(\%)$ & $0.50-1.00$ & 25 \\
Aliphatic proton linked to a $\beta$ carbon, $\mathrm{H}_{\beta}(\%)$ & $1.00-1.85$ & 54 \\
Aliphatic proton linked to a $\gamma$ carbon, $\mathrm{H}_{\gamma}(\%)$ & $1.85-4.50$ & 15 \\
Aromatic carbons, Ar-C $(\%)$ & $118-130.0$ & 40 \\
Aliphatic carbons, Al-C $(\%)$ & $0.0-70.0$ & 60 \\
Peripheric carbons, p-C & $129-137.0$ & 26 \\
Internal aromatic carbon, $\mathrm{C}_{\text {in }}$ & $118-130.0$ & 10 \\
Ratio p-C/Ar-C & - & 0.73 \\
Aromaticity factor, A & - & 0.4 \\
Average chain carbons, $\mathrm{n}$ & - & 4 \\
Substitution percentage of the aromatic ring, $\mathrm{Ar}_{\text {sus }}(\%)$ & - & 71 \\
\hline
\end{tabular}

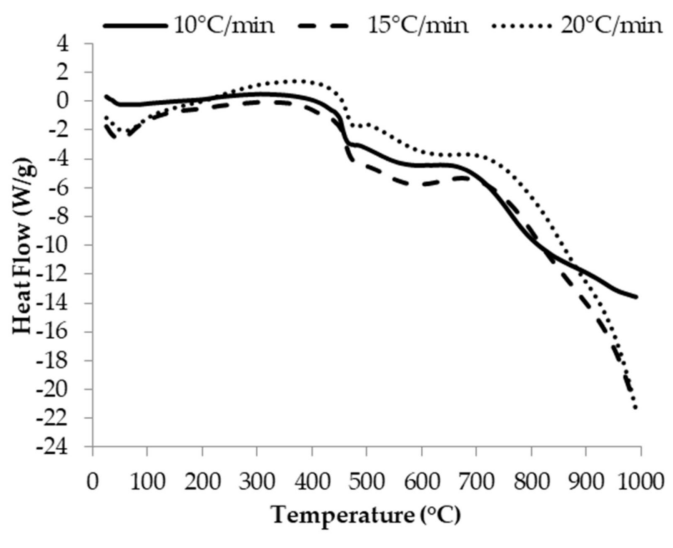

(a)

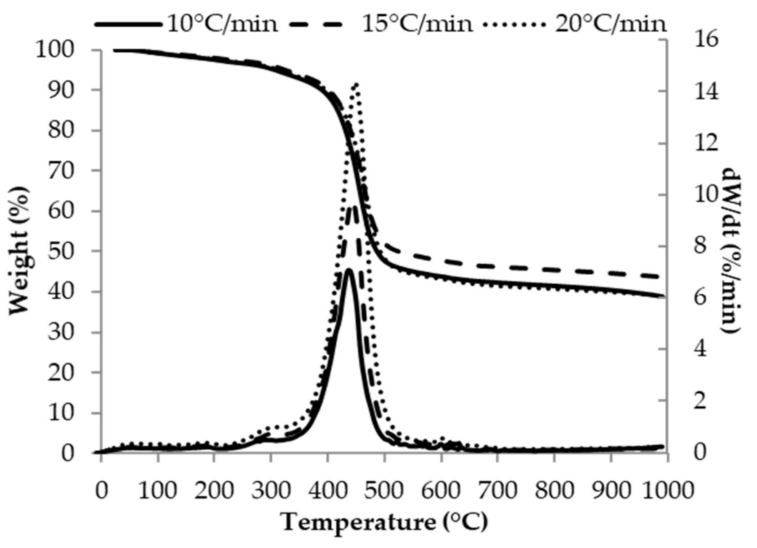

(b)

Figure 3. (a) DSC; (b) TGA/DTA curves of the asphaltenes from the Castilla crude oil at different heating rates $\left(10,15\right.$, and $\left.20^{\circ} \mathrm{C} / \mathrm{min}\right)$.

TGA/DTA plots were similar in shape at different heating rates $\left(10,15\right.$, and $\left.20^{\circ} \mathrm{C} / \mathrm{min}\right)$, but differed slightly in their location (Figure $3 b$ ). This can be explained because the increase in the heating rate causes that the time to reach the pyrolysis temperature to become shorter. It also benefits the reaction development, while the temperature gradient between the interior of the sample and its surface increases. Thus, the superficial light products are carried outside by the gas flow, and those products 
inside the solid evaporate at a higher temperature, which causes that the temperature of the maximum weight loss rate moves to a hotter zone.

Considering the DTA profiles, mass loss was divided into three main stages: below $200{ }^{\circ} \mathrm{C}$, between 200 and $550{ }^{\circ} \mathrm{C}$, and above $550{ }^{\circ} \mathrm{C}$. The first stage was the drying or degassing, where the adsorbed water and gases, including some low molecular weight components, were released from the untreated samples. In this stage, the derivative weight loss $(\mathrm{dw} / \mathrm{dt})$ was approximately zero, and the weight loss was small $(2.12 \%)$, indicating that the content of water and low molecular weight components was negligible, and that few chemical reactions took place. These low-molecular-weight compounds in the asphaltenes could come from their previous processes of extraction and purification. The onset of pyrolysis $\left(330^{\circ} \mathrm{C}\right)$ was high for the asphaltene, and there was a $5 \%$ weight loss at this temperature. This result served as a base indicator for the subsequent process of pyrolysis between 330 and $450{ }^{\circ} \mathrm{C}$, since from the higher temperature $\left(450^{\circ} \mathrm{C}\right)$, the mass-loss rate decreased considerably, according to DTA curves.

\subsection{Chemical Composition of the Asphaltenes and Cokes}

The effect of the pyrolysis temperature on the molecular structure of the asphaltenes was evaluated based on the variations of atomic ratios of $\mathrm{S} / \mathrm{C}, \mathrm{N} / \mathrm{C}$, and $\mathrm{H} / \mathrm{C}$ (Table 3). The $\mathrm{S} / \mathrm{C}$ and N/C ratios with typical values of 0.02 did not depend on the process temperature. Likewise, the quantity of $\mathrm{N}$ and $\mathrm{S}$ atoms was approximately constant in the empirical formulas calculated for asphaltenes. So, the groups containing $\mathrm{S}$ and $\mathrm{N}$ atoms remained unchanged in the nucleus of asphaltenes. The $\mathrm{H} / \mathrm{C}$ ratio of the asphaltenes decreased from 1.1 to $0.6\left(330-450{ }^{\circ} \mathrm{C}\right)$, indicating that the aromaticity increased when the pyrolysis temperature raised. The pyrolysis reactions primarily reduced the molecular size as denoted by the change of the formula weight. Moreover, the heating value (HHV) of asphaltenes decreased from 39,649 to $22,474 \mathrm{~J} / \mathrm{kg}$, showing that the molecular structure becomes less reactive in the process of thermal cracking.

Table 3. Percentage of $\mathrm{C}, \mathrm{H}, \mathrm{N}, \mathrm{S}$ and $\mathrm{O}$ by elemental analysis and higher heating value (HHV) of original and pyrolyzed asphaltenes, coke and liquid product at different temperatures $(\mathrm{T})$.

\begin{tabular}{|c|c|c|c|c|c|c|c|c|c|c|c|c|}
\hline \multirow{2}{*}{$\mathrm{T}\left({ }^{\circ} \mathrm{C}\right)$} & $\mathrm{C}$ & $\mathbf{H}$ & $\mathbf{N}$ & $\mathbf{O}$ & $\mathbf{S}$ & \multirow{2}{*}{$\mathrm{H} / \mathrm{C}$} & \multirow{2}{*}{$\mathrm{N} / \mathrm{C}$} & \multirow{2}{*}{$\mathrm{O} / \mathrm{C}$} & \multirow{2}{*}{$\mathrm{S} / \mathrm{C}$} & \multirow{2}{*}{$\begin{array}{l}\text { HHV } \\
\text { (J/kg) }\end{array}$} & \multirow{2}{*}{ CEF } & \multirow{2}{*}{$\underset{(\mathrm{g} / \mathrm{mol})}{\mathrm{FW}}$} \\
\hline & \multicolumn{5}{|c|}{$(w t \%) *$} & & & & & & & \\
\hline \multicolumn{13}{|c|}{ Asphaltenes } \\
\hline $25^{1}$ & 84 & 7.8 & 1.5 & 1.2 & 4.7 & 1.1 & 0.02 & 0.01 & 0.02 & 39,649 & $\mathrm{C}_{91} \mathrm{H}_{101} \mathrm{NOS}_{2}$ & 1289 \\
\hline 330 & 85 & 7.6 & 1.5 & 2.0 & 4.2 & 1.1 & 0.02 & 0.02 & 0.02 & 39,336 & $\mathrm{C}_{65} \mathrm{H}_{70} \mathrm{NOS}$ & 913 \\
\hline 360 & 82 & 6.8 & 1.6 & 4.9 & 4.3 & 1.0 & 0.02 & 0.04 & 0.02 & 37,049 & $\mathrm{C}_{61} \mathrm{H}_{60} \mathrm{NOS}$ & 855 \\
\hline 390 & 77 & 4.9 & 1.8 & 7.7 & 4.2 & 0.8 & 0.02 & 0.07 & 0.02 & 32,066 & $\mathrm{C}_{50} \mathrm{H}_{38} \mathrm{NO}_{2} \mathrm{~S}$ & 717 \\
\hline 420 & 77 & 4.2 & 2.0 & 12.7 & 3.8 & 0.6 & 0.02 & 0.12 & 0.02 & 30,301 & $\mathrm{C}_{46} \mathrm{H}_{30} \mathrm{NO}_{2} \mathrm{~S}$ & 661 \\
\hline 450 & 64 & 3.2 & 2.0 & 27.7 & 3.7 & 0.6 & 0.03 & 0.32 & 0.02 & 22,474 & $\mathrm{C}_{46} \mathrm{H}_{27} \mathrm{NO}_{3} \mathrm{~S}$ & 674 \\
\hline \multicolumn{13}{|c|}{ Coke } \\
\hline 360 & 84 & 7.1 & 1.7 & 2.8 & 4.4 & 1.0 & 0.02 & 0.03 & 0.05 & 30,286 & $\mathrm{C}_{58} \mathrm{H}_{58} \mathrm{NOS}$ & 817 \\
\hline 390 & 85 & 4.6 & 2.1 & 3.6 & 4.7 & 0.6 & 0.02 & 0.04 & 0.06 & 31,072 & $\mathrm{C}_{48} \mathrm{H}_{31} \mathrm{NO}_{2} \mathrm{~S}$ & 686 \\
\hline 420 & 85 & 3.9 & 2.1 & 4.6 & 4.4 & 0.5 & 0.02 & 0.05 & 0.05 & 30,889 & $\mathrm{C}_{52} \mathrm{H}_{28} \mathrm{NO}_{2} \mathrm{~S}$ & 731 \\
\hline 450 & 86 & 3.2 & 1.9 & 5.8 & 3.1 & 0.4 & 0.02 & 0.07 & 0.04 & 30,612 & $\mathrm{C}_{53} \mathrm{H}_{23} \mathrm{NO}_{3} \mathrm{~S}$ & 754 \\
\hline
\end{tabular}

* Standard deviations were $\pm 2.0, \pm 1.0, \pm 0.2, \pm 2.0, \pm 0.6$ for $\mathrm{C}, \mathrm{H}, \mathrm{N}, \mathrm{O}$ and $\mathrm{S}$, respectively. CEF: Condensed empirical formula, FW: Formula weight. ${ }^{1}$ Non-pyrolyzed asphaltenes corresponds to $25^{\circ} \mathrm{C}$.

\subsection{FTIR Analysis}

FTIR spectra of the reacted asphaltenes (Supplementary Figure S1) showed the presence of polynuclear aromatic clusters by the bands of the C-H cluster, skeletal vibrations of $\mathrm{C}-\mathrm{C}$ stretching on the ring (1500-1400 $\mathrm{cm}^{-1}$ and $\left.1505-1585 \mathrm{~cm}^{-1}\right)$, weak combinations $\left(2000-1650 \mathrm{~cm}^{-1}\right)$, and aromatic C-H stretching (3070-3000 $\left.\mathrm{cm}^{-1}\right)$. These bands were associated with heteroaromatic compounds, especially pyrrolic and pyridine compounds. Skeletal vibrations $\left(1600-1300 \mathrm{~cm}^{-1}\right)$ were detected 
from heteroaromatic groups such as pyridine derivatives. Organic sulfur compounds were also present due to the vibrations of the C-S bonds $\left(700-600 \mathrm{~cm}^{-1}\right)$. Two intense bands appeared in the asphaltene spectra, (2915 and $2952 \mathrm{~cm}^{-1}$ ) due to the tension vibration of the $\mathrm{CH}_{3}$ - and $\mathrm{CH}_{2}$ - clusters in the linear chains of the initial asphaltenes. As the pyrolysis temperature increased, the intensity of signals decreased, especially at temperatures between 420 and $450{ }^{\circ} \mathrm{C}$. The FTIR spectra also showed low-intensity bands associated with the carbonyl group at $1600-1800 \mathrm{~cm}^{-1}$. Signals related to $-\mathrm{OH}$ and $-\mathrm{NH}$ groups were identified at $3000-3600 \mathrm{~cm}^{-1}$ with low intensity and are often linked with aggregations of asphaltene molecules by hydrogen bonds.

FTIR spectroscopy allowed a comparison of the pyrolyzed asphaltenes because the extinction coefficients had no significant variation between each other, and areas were normalized against the $\mathrm{C}-\mathrm{H}$ stretching absorptions. The values of the relative aromaticity, aromatic condensation degree, di-substitution degree, aromatic substitution degree, and ramification degree, were calculated at the different pyrolysis temperatures (Table 4). Consequently, an approximation was made to the chemical transformation during the thermal pyrolytic treatment. In general, the parameter values increased with temperature. The relative aromaticity raised significantly (from 0.3 to 2.0 ) when the pyrolysis temperature increased (from 330 to $450{ }^{\circ} \mathrm{C}$ ), which was congruent with the results of elemental analysis (Table 3). These results also suggested the separation of the lateral aliphatic chains of the original molecules and the formation of condensed aromatic rings. The degree of aromatic condensation remained constant until a reaction temperature of $420^{\circ} \mathrm{C}$. Then, it showed a clear tendency to enhance as the pyrolysis temperature increased until $450^{\circ} \mathrm{C}$ (from 0.9 to 1.5). It evidenced the possible formation of new aromatic structures in resonance with pre-existing aromatic structures in the later stage of pyrolysis. The degree of disubstitution also rose (from 1.1 to 1.7), which indicated the formation of new bonds with aromatic rings. Likewise, the ramification degree increased, which suggested the production of new C-C links. This led to the generation of naphthenic rings linked to the aromatic rings and increasing the ramification of the lateral clusters.

Table 4. Structural and chemical parameters of asphaltenes as a function of temperature (T) during pyrolysis processes between $330-470{ }^{\circ} \mathrm{C}$, determined through IR data, and empiric condensed formula.

\begin{tabular}{cccccc}
\hline T $\left({ }^{\circ} \mathbf{C}\right)$ & RA & ACD & DD & ASD & RD \\
\hline $25^{1}$ & 0.3 & 0.9 & 1.1 & 0.9 & 0.7 \\
330 & 0.3 & 0.8 & 0.9 & 0.9 & 0.3 \\
360 & 0.3 & 0.9 & 1.1 & 0.8 & 0.5 \\
390 & 1.2 & 0.4 & 0.9 & 0.5 & 1.3 \\
420 & 2.1 & 0.9 & 0.7 & 1.4 & 1.5 \\
450 & 2.0 & 1.5 & 1.7 & 0.9 & 1.2 \\
\hline \multicolumn{7}{c}{ Non-pyrolyzed asphaltenes corresponds to $25^{\circ} \mathrm{C}}$.
\end{tabular}

\subsection{XRD Analysis}

The crystallite parameters of the original and reacted asphaltenes were determined from the deconvolved XRD standards (Supplementary Figure S2) using the Yen modified equations [6]. The aromaticity factor increased with the temperature and reached a value of 1.00 at $390{ }^{\circ} \mathrm{C}$ (Table 5), which indicates the elimination of the aliphatic groups. On the one hand, the parameter of the number of molecules in the cluster $M e(9 \pm 1)$ remained without significant changes when the pyrolysis temperature rose. On the other hand, the parameter $L a$ decreased from 14 to $9 \AA$, which showed that several functional clusters, belonging to the core of the original asphaltenes, were transferred to the liquid fraction. This decrease in $L a$ also reduced the weight of the aromatic sheet (from 577 to $293 \AA$ ). 
Table 5. Structural parameters of asphaltenes as a function of temperature (T) determined by XRD during pyrolysis between 330 and $420^{\circ} \mathrm{C}$.

\begin{tabular}{cccccccc}
\hline $\mathbf{T}\left({ }^{\circ} \mathbf{C}\right)$ & $\mathbf{f A}$ & $\mathbf{d m}(\mathbf{A})$ & $\mathbf{d} \boldsymbol{\gamma}(\AA)$ & $\mathbf{L c}(\mathbf{A})$ & $\mathbf{M e}$ & $\mathbf{L a}(\AA)$ & WAD $^{*}$ \\
\hline $255^{1}$ & 0.4 & 3.5 & 6.3 & 34 & 10 & 14 & 577 \\
330 & 0.7 & 3.6 & 6.4 & 29 & 8 & 15 & 694 \\
360 & 0.8 & 3.6 & 5.9 & 36 & 10 & 13 & 531 \\
390 & 1.0 & 3.5 & - & 36 & 10 & 9 & 293 \\
420 & 1.0 & 3.5 & - & 32 & 9 & 9 & 293 \\
\hline * WAD: Weight of the aromatic sheet. ${ }^{1}$ Non-pyrolyzed asphaltenes corresponds to $25^{\circ} \mathrm{C}$.
\end{tabular}

\subsection{Analysis of the Liquid Products}

The liquid product obtained at $390^{\circ} \mathrm{C}$ had the highest calorific value $(43,199 \mathrm{~J} / \mathrm{kg})$ for this type of product (Table 6). Considering that the main property of fuel is its calorific value, this fraction appears to be the most promising for fuel production. Additionally, liquid products were composed of $70 \%$ saturated hydrocarbons and only $5 \%$ polar aromatics, as indicated by the SARA analysis (Figure 4), which supports its high potential as a fuel. Therefore, the results of the chromatographic separation of SARA fractions coincided with those of the elemental analysis (Supplementary Figure S3), whereby the highest $\mathrm{H} / \mathrm{C}$ ratio (1.6) was obtained at $390^{\circ} \mathrm{C}$. This indicated a larger quantity of saturated hydrocarbons (Supplementary Figure S4) in comparison with liquid fractions produced at the other temperatures. The concentration of saturates decreased after $390^{\circ} \mathrm{C}$. On the contrary, the naphthene (Supplementary Figure S5) and polar aromatics (Supplementary Figure S6) increased with temperature, thus suggesting the occurrence of processes where the formation of the gaseous products occurred as a result of the scission of aliphatic bonds from the liquid products.

Table 6. Percentage of $\mathrm{C}, \mathrm{H}, \mathrm{N}, \mathrm{S}$ and $\mathrm{O}$ by elemental analysis and higher heating value (HHV) of liquid product at different temperatures $(\mathrm{T})$.

\begin{tabular}{|c|c|c|c|c|c|c|c|c|c|c|}
\hline \multirow{2}{*}{$\mathrm{T}\left({ }^{\circ} \mathrm{C}\right)$} & $\mathrm{C}$ & $\mathbf{H}$ & $\mathbf{N}$ & O & $S$ & \multirow{2}{*}{$\mathrm{H} / \mathrm{C}$} & \multirow{2}{*}{$\mathrm{N} / \mathrm{C}$} & \multirow{2}{*}{$\mathrm{O} / \mathrm{C}$} & \multirow{2}{*}{$\mathrm{S} / \mathrm{C}$} & \multirow{2}{*}{$\begin{array}{l}\text { HHV } \\
(\mathrm{J} / \mathrm{kg})\end{array}$} \\
\hline & \multicolumn{5}{|c|}{$(w t \%) *$} & & & & & \\
\hline 330 & 78 & 9.8 & 0.1 & 9.2 & 2.9 & 1.5 & 0.001 & 0.12 & 0.04 & 39,308 \\
\hline 360 & 81 & 11.0 & 0.3 & 4.9 & 2.8 & 1.6 & 0.003 & 0.07 & 0.03 & 42,686 \\
\hline 390 & 82 & 11.0 & 0.3 & 3.7 & 3.0 & 1.6 & 0.003 & 0.05 & 0.04 & 43,199 \\
\hline 420 & 82 & 9.5 & 0.2 & 5.8 & 2.5 & 1.4 & 0.002 & 0.07 & 0.03 & 40,603 \\
\hline 450 & 79 & 8.7 & 0.2 & 9.1 & 3.0 & 1.3 & 0.002 & 0.12 & 0.04 & 38,006 \\
\hline
\end{tabular}

* Standard deviations were $\pm 2.0, \pm 1.0, \pm 0.2, \pm 2.0, \pm 0.6$ for $\mathrm{C}, \mathrm{H}, \mathrm{N}, \mathrm{O}$ and S, respectively. ${ }^{1}$ Non-pyrolyzed asphaltenes correspond to $25^{\circ} \mathrm{C}$.

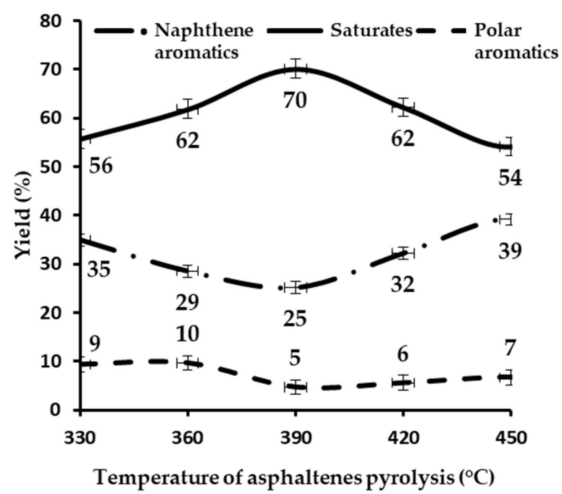

Figure 4. SARA analysis of liquid products from the pyrolysis of the asphaltenes at $330-450{ }^{\circ} \mathrm{C}$.

In addition to carrying out the quantitative SARA analysis of the liquid pyrolysis product, the GC-MS was obtained from the saturates (Supplementary Figure S4) to better understand its 
chemical composition. The saturated fraction consisted mainly of a homologous series of n-alkanes in the range of C9-C30, with base peaks at $43 \mathrm{~m} / \mathrm{z}$ and $57 \mathrm{~m} / \mathrm{z}$. These chains were directly derived from the original structure of the asphaltenes. So, longer alkyl chains were formed from the pyrolysis of the rings or branched structures. The most likely occurrence of such chains is as alkyl substituents in aromatic cores, as suggested by Liu et al. [22]. In addition to this, the presence of long chains of n-alkyl groups on the asphaltene structures was consistent with the results obtained previously by ${ }^{1} \mathrm{H}$ and ${ }^{13} \mathrm{C}$ NMR (Table 2). The GC-MS analysis of the liquid product without previous separation also supported the identity of its volatile fraction. Abundant aromatic biological markers (such as alkylbenzenes) were identified (Supplementary Figure S7), using the MS-NIST library. Homologous series of straight-chained alkanes and alkenes were also found.

The infrared spectra of naphthene aromatics indicated that they presented substituted aromatic rings and numerous aliphatic chains, which were identified through the high-intensity signals between 1920 and $1850 \mathrm{~cm}^{-1}$ corresponding to the stretching vibrations of the methyl and methylene groups. They also presented some groups type C-O-C, Ar-O-C, S=O, or S-O that were detected by the signals of the region between 1200 and $1000 \mathrm{~cm}^{-1}$ (Supplementary Figure S5). On the other hand, the FT-IR spectra of the polar aromatics (Supplementary Figure S6) showed the abundance of some important functional groups. The saturated groups present in this fraction had abundant absorptions at 2959, 2874,1457 , and $1381 \mathrm{~cm}^{-1}$. Aromatic groups produced specific bands in the region of $900-650 \mathrm{~cm}^{-1}$. A broad absorption band at $1749 \mathrm{~cm}^{-1}$ indicated the presence of esters, ketones, amides, or acids. A characteristic band of the $\mathrm{O}-\mathrm{H}$ and $\mathrm{N}-\mathrm{H}$ stretching vibrations of alcohols and amines was observed at $3297 \mathrm{~cm}^{-1}$. These results coincided with previous reports [23] which indicated that polar aromatics present aromatic and naphthenic structures with polar groups, as well as unsaturated and cyclic hydrocarbons intertwined with nitrogen and sulfur heteroatoms.

\subsection{Analysis of the Gaseous Products}

The GC analysis of gaseous products showed that all gases were simultaneously produced but in different proportions (Figure 5a). Thus, the gaseous compounds produced at the different temperatures of pyrolysis had approximately the same retention times, and particularly the intensity of the first peak (corresponding to methane) increased when the pyrolysis temperature of the asphaltenes was higher. Moreover, the GC-MS chromatogram of the gas (Figure 5b) confirmed that the three more intense peaks (the first and second peaks were unresolved) consisted primarily of the compounds methane and ethane, propane, and pentane. In the FTIR gases spectra (Supplementary Figure S8), the bands corresponding to the stretching vibrations of $-\mathrm{CH}_{3}$ and $-\mathrm{CH}_{2}$ groups were observed at 2967 and $3015 \mathrm{~cm}^{-1}$, indicating an abundance of saturated compounds.

\subsection{Hypothetical Structures and Transformation of Asphaltenes during Pyrolysis}

The Ni (382 mg/kg) and V (1851 mg/kg) concentrations reported here (Table 1) were comparable to the typical values published in the literature (1-1200 ppm). In the same way, the molecular weight $(1492 \pm 206 \mathrm{~g} / \mathrm{mol})$ was similar to the one obtained by Morantes et al. [24] for asphaltenes from Castilla crude oil (1200 g/mol). It was congruent with the results of elemental analysis (Table 3 ) and with the theoretical molecular weight $(1289 \mathrm{~g} / \mathrm{mol})$ corresponding to the average molecular formula of the asphaltenes $\left(\mathrm{C}_{91} \mathrm{H}_{101} \mathrm{NOS}_{2}\right)$. Additionally, the chemical composition of asphaltenes according to the results of ${ }^{1} \mathrm{H}$ and ${ }^{13} \mathrm{C}$ NMR, as well as FTIR and XRD, allowed the determination of the amount of each type of $\mathrm{H}$ and $\mathrm{C}$ as follows: C aliphatic number 55, C aromatic number 36, C aliphatic chains length 4, $\mathrm{H}$ aliphatic number $95, \mathrm{H}$ aromatic number 6 , and the ratio of the $\mathrm{N}, \mathrm{O}$, and $\mathrm{S}$ heteroatoms in the initial asphaltenes. Moreover, other parameters had the following values: $\mathrm{H}_{\alpha}$ was $26, \mathrm{H}_{\beta}$ was 54 , and $\mathrm{H}_{\gamma}$ equals 15. The aromaticity factor (0.4), the length of the aliphatic lateral chain (4), and the maximum substitution percentage of the aromatic rings (71\%) suggested a moderate aromatic structure of the asphaltenes (Table 2). These results were similar to those previously published by Savage et al. [18]. 


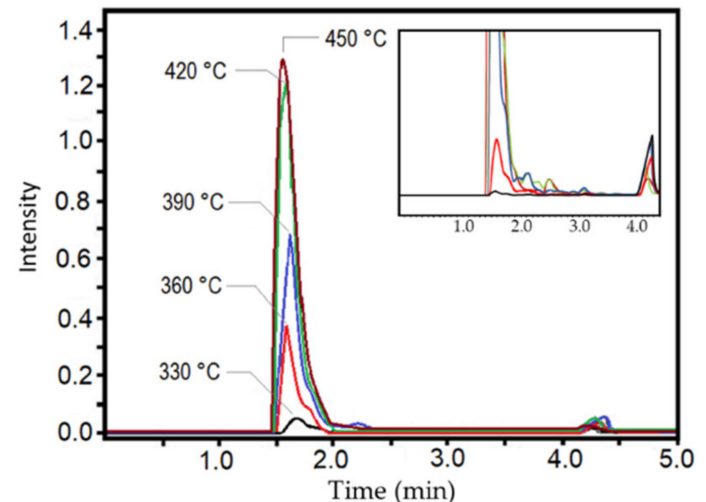

(a)

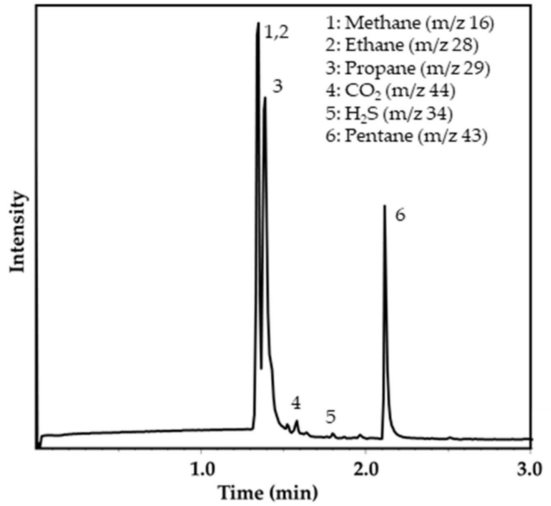

(b)

Figure 5. (a) The GC analysis of the gaseous product at different temperatures of the asphaltenes pyrolysis and; (b) identified compounds by GC-MS in the gaseous product at $390^{\circ} \mathrm{C}$.

The asphaltenes constitute a complex mixture of a broad group of compounds. However, it is possible to propose an average structure, considering the pyrolysis results and the previous findings of their characteristics. So, it can be useful to take advantage of the chemical transformations of asphaltenes for their potential applications. In this case, the limitations on the location of heteroatoms suggested that $\mathrm{N}$ was in the aromatic fraction, $\mathrm{S}$ was in thiophenes and thioethers, and $\mathrm{O}$ was in phenolic derivatives and ethers. All the results were compared (Table 4), and a hypothetical average molecular structure was proposed for the original asphaltenes from Castilla crude oil.

The diagram of the structure of the original asphaltenes (Figure 6) remarks that the interchain distance was constant $(3.5 \AA)$ during thermal conversion and was within the average range (3.4-3.7 $\AA$ ) reported by $\mathrm{Al}$ Humaidan et al. [25]. In addition to the interlayer distance $(d \gamma)$ between the aromatic sheets, this parameter was related to planarity and showed the absence of distortions of the aromatic ring structures, which could have been caused by the inclusion of atoms, saturation, or naphthenic and aliphatic structures. The distance $d \gamma$ presented a similar behavior than $d m$ since the aromatic sheets remained at an equal distance with the aliphatic chains attached to them. The $d \gamma$ (5.9-6.4 $\AA$ ) were congruent with those reported (4.4-6.2 $\AA$ ) by AlHumaidan et al. [25] and Liao et al. [26]. In the same way, the value for the average diameter of the aromatic sheets of the asphaltenes (14 $\AA$ ) was in the range of typical values (10.4-18.1 $\AA$ ). This was close to the values obtained by the direct molecular imaging method corresponding to an asphaltene molecule with approximately seven fused aromatic rings [25]. Thus, each asphaltene molecule initially contained a long axis of seven fused rings (size $\sim 14 \AA$ ). Then, the value in the aromatic sheet decreased $(9 \AA)$ at $390^{\circ} \mathrm{C}$, which was equivalent to approximately six fused rings.

The $\mathrm{H} / \mathrm{C}, \mathrm{S} / \mathrm{C}$, and $\mathrm{N} / \mathrm{C}$ ratios are average values because the asphaltenes are a mixture of thousands of molecules [27]. The S/C ratio (0.02) did not change during pyrolysis. It indicated that the $\mathrm{S}$ atoms remained at thermally stable positions such as alkyl-substituted derivatives of dibenzothiophene [28]. The $\mathrm{H} / \mathrm{C}$ ratio in the original asphaltenes (1.1) was lower than the one reported in "light" asphaltenes ( 2.0) from conventional crudes [23,24]. The variation in the H/C ratio (Supplementary Figure S9) suggested that the complete process of asphaltenes cracking occurred primarily in three stages. According to Sjöblom et al. [29] and Zhao et al. [30], they are early, middle, and later stages. These stages are related to reactions to generate coke. In general, they are dealkylation of the aliphatic lateral chains, possible polymerization by radical species, cyclization and dehydrogenation of the $\mathrm{C}-\mathrm{H}$ groups, and condensation of the aromatic rings. 

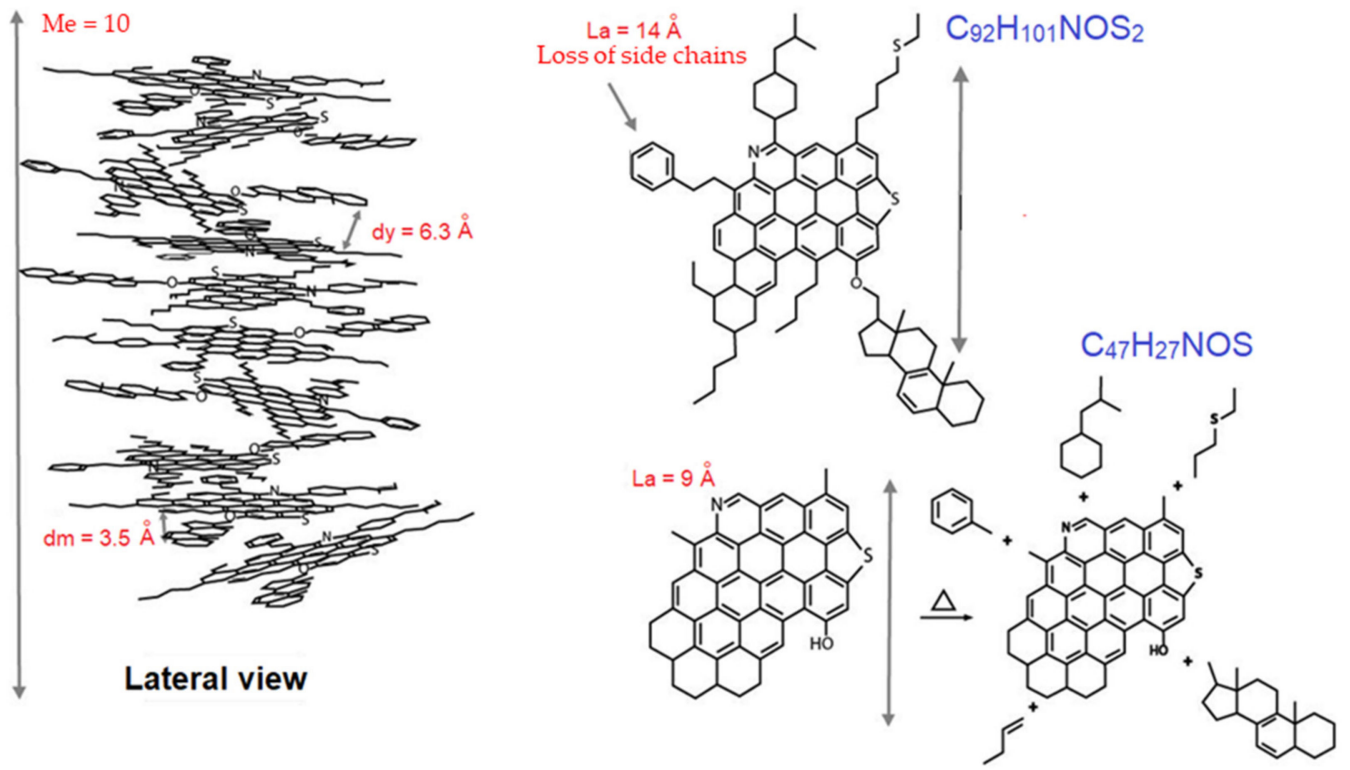

Figure 6. Hypothetical average molecular structure of the original asphaltenes cluster of Castilla crude oil (lateral view), and the proposed mechanism of transformation of an asphaltene molecule in new compounds with lower molecular weight (abbreviated).

More precisely, the pyrolysis of asphaltenes includes different reactions, such as the combination of naphthenic rings, the cyclization of alkyl substituents, the dehydrogenation of the cycloalkyl groups, the dealkylation, and condensation of aromatic rings [30]. Gray et al. [31] proposed that aromatic rings of asphaltenes do not crack at temperatures between $330-550{ }^{\circ} \mathrm{C}$, so the polycyclic part of the layer unit is considered thermally stable and is conserved during pyrolysis. Additionally, the mechanism of free radical reaction abstracts hydrogens from the naphthenic and paraffinic fractions leading to generate more double bonds and aromatic rings in the core of the asphaltenes [32,33].

The aliphatic $\mathrm{C}-\mathrm{C}$ bonds at the alkyl aromatic, alkyl hydroaromatic, and alkyl naphthenic positions of the asphaltenes, along with the links involving peripheral substituents with heteroatoms, constitute the thermolabile groups, which can act as initiators of the free radical reaction. In the case of the alkylbenzene groups, the weakest link is the one between the $C \alpha$ and $C \beta$ in the alkyl chain. It is expected that the homolytic dissociation of this C-C bond is the fastest initiation step of pyrolysis, as suggested by Savage [34]. Thus, the steps to obtain the pyrolysis products included the initiation of the chain in the early stage of the reaction at $330^{\circ} \mathrm{C}$, through the breaking of thermolabile C-O bonds of the ether groups and mononuclear homolysis in position $\alpha$ to the aromatic core to liberate the phenyl derivatives, as outlined in Figure 6.

During pyrolysis between 330 and $420^{\circ} \mathrm{C}$, alkyl substituents were continuously liberated from the asphaltenes core. Moreover, hydrogen concentration was reduced via the cyclization of the alkyl chains. The union of two alkyl radicals could produce alkanes and alkenes with longer chains. They remained reactive and continued to crack and made more products to generate larger alkyl structures, as verified by Alshareef [32]. On the contrary, homolytic dissociation occurred to generate lighter fractions. The $\beta$-cleavage could also fractionate the lineal hydrocarbons in the liquid, producing the methane in the gaseous fraction, which showed an increase in concentration with the pyrolysis temperature. Isobutylcyclohexane was another liquid product. It could be formed through cyclization of long-chain alkanes, such as heptane, occurring the isomerization, and addition of C-6 to C- 1 of the same radical. The radical addition step allowed the cyclization of those alkyl chains, whereas a third chain underwent $\beta$-cleavage of the bond with the cycloalkyl derivative and was thereby released. 


\subsection{Pyrolysis of Asphaltenes}

The behavior presented by the asphaltenes during pyrolysis was congruent with the previously explained potential mechanism of reaction. Thus, the material balance showed that the content of asphaltenes decreased until zero at $450{ }^{\circ} \mathrm{C}$ (Figure 7). At this temperature, the asphaltenes were completely decomposed to produce mainly coke and gases (methane, ethane, propane, and pentane). This was consistent with the results found by Douda et al. [35] for Maya crude asphaltenes, and by Yasar et al. [36] for light and heavy Arabian crudes.

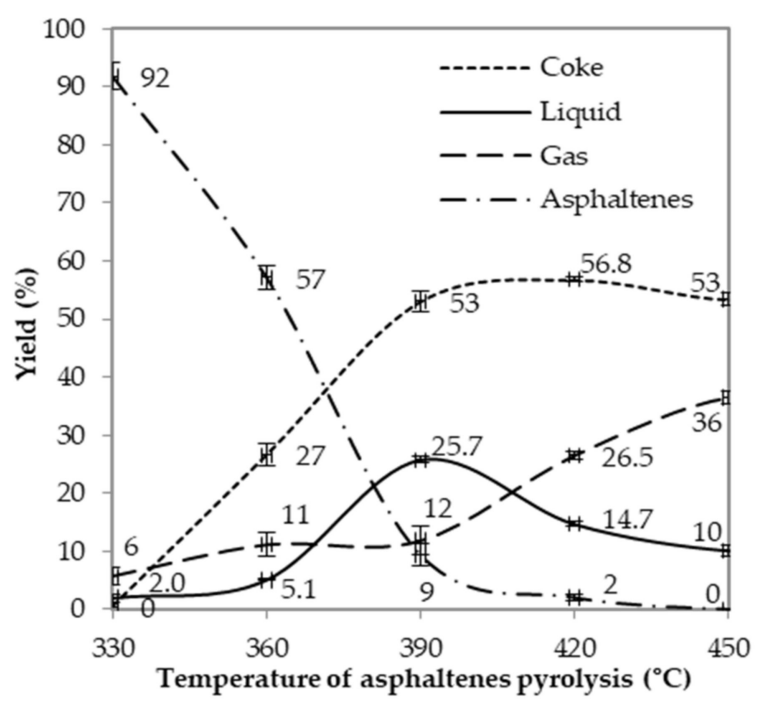

Figure 7. Mass balance during pyrolysis of the asphaltenes from the Castilla crude oil between $330-450{ }^{\circ} \mathrm{C}$.

Regarding the gaseous product, its efficiency tended to increase over $390{ }^{\circ} \mathrm{C}$ (from 12 to $36 \%$ ). The liquid product yield consistently reached a maximum at $390{ }^{\circ} \mathrm{C}(25.7 \%)$ and then decreased. This yield was high due to the high content of aliphatic carbons of the asphaltenes (Table 2). This suggested that the liquid product generated from primary reactions underwent secondary pyrolysis, which produced gases. Trauth et al. [37] studied the pyrolysis of Maya and Honda asphaltenes at 400,425 , and $450{ }^{\circ} \mathrm{C}$ and reported a similar result in their study. Moreover, Akmaz et al. [32] studied the pyrolysis of Raman crude oil asphaltenes and found the same behavior of the liquid product. According to them, the maximum liquid product yield was due to the intense degradation of the asphaltene molecules via the breakdown of carbon-carbon and relatively strong carbon-heteroatom bonds. Consequently, the liquid fraction obtained at $450{ }^{\circ} \mathrm{C}$ might contain more thermally stable fractions from the asphaltene molecules and possible products of the secondary reactions, as suggested by Grin'ko et al. [38]. The result from an asphalt waste, such as asphaltenes, with up to $26 \%$ of liquid products that can be useful as a gasoline-type fuel was very satisfactory.

\subsection{Perspectives}

Our results hinted that the pyrolytic solid fractions obtained at $450{ }^{\circ} \mathrm{C}$ consisted of a series of compounds that can be used to produce stable materials based on highly condensed aromatic structures. For example, inert and hydrophobic coatings, based on pyrolytic coke, can be used for biomedical surfaces. Other types of stable materials, such as paints, could be fabricated exploiting of $\pi$-conjugated systems in coke. Taking into consideration that conjugated and partially conjugated systems are thermodynamically more stable than non-conjugated systems, the idea of the potential applicability of coke is reinforced. In the same way, liquid and gaseous products showed a significant prospect to be employed as fuels. They are also a source of chemical precursors, based mainly on saturated and unsaturated hydrocarbons, which can be used after a previous separation. 


\section{Conclusions}

The range of pyrolysis was determined based on the TGA/DSC analysis between 330 and $450{ }^{\circ} \mathrm{C}$. The average chemical structure of asphaltenes from Colombian Castilla heavy crude oil and its transformation during pyrolysis was determined through a set of analytical techniques, such as GPC, ${ }^{1} \mathrm{H}$, and ${ }^{13} \mathrm{C}$ NMR, elemental analysis, FTIR, and XRD. Original asphaltenes contained four carbon atoms in the aliphatic chains. They presented approximately 26 peripheral aromatic carbons, about ten internal aromatic carbons, and only six aromatic hydrogens in their core. An approach to the free radical mechanism was used to explain the behavior of asphaltenes and products during pyrolysis. The different analyses performed showed a trend toward an increase in aromaticity with the pyrolysis temperature, which suggested a loss of aliphatic chains, an increase in the number of unsaturated bonds, and the condensation of the aromatic rings. In this way, the $\mathrm{H} / \mathrm{C}$ ratio of the asphaltenes decreased (from 1.1 to 0.6 ), the relative aromaticity given by FTIR increased (from 0.3 to 2.0 ), and the aromaticity factor obtained through XRD increased (from 0.4 to 1.0) when the temperature was $450{ }^{\circ} \mathrm{C}$. The loss of aliphatic groups as the pyrolysis temperature increased caused that the aromatic sheets underwent a decrease in size and molecular weight, even though the distance between each sheet and the number of associated aromatic layers in a nanocluster remained constant. The diameter of the aromatic layers of the original asphaltenes showed the presence of a long axis of the sheet that consisted of seven fused rings. The reduction of this parameter when temperature increased indicated the loss of substituent clusters linked to the aromatic core. The complete conversion of asphaltenes into coke, liquid and gaseous products was reached at $450{ }^{\circ} \mathrm{C}$. The main volatile products detected were derivatives of benzene, alkenes, aromatic hydrocarbons, and linear alkanes of $C_{1}-C_{30}$. At $390{ }^{\circ} \mathrm{C}$, the liquid fraction presented the best yield (25.7\%), the maximum calorific value $(43,199 \mathrm{~J} / \mathrm{kg})$, and the highest percentage of saturates (70\%) with a minimum content of polar aromatics $(7 \%)$, making it the most promising liquid product to be used as a fuel. In this regard, the liquid and gaseous products have potential use as fuels and as a source of low molecular-weight by-products.

Supplementary Materials: The following materials are available online at http:/www.mdpi.com/2227-9717/8/ 12/1644/s1: "Figure S1. FTIR spectra of the original (1) and pyrolyzed asphaltenes at temperatures $\left({ }^{\circ} \mathrm{C}\right):(2) 330$, (3) 360, (4) 390, (5) 420, (6) 450", "Figure S2. Diffractogram of the (a) original asphaltenes and; (b) coke obtained at $390^{\circ} \mathrm{C}^{\prime \prime}$, "Figure S3. H/C ratio of the liquid product against the pyrolysis temperature", "Figure S4. GC-MS analysis of the saturates fraction from the liquid product obtained through asphaltenes pyrolysis at $390^{\circ} \mathrm{C}^{\prime \prime}$, "Figure S5. FTIR spectra of the naphthene aromatics from the liquid product obtained to the temperature $\left({ }^{\circ} \mathrm{C}\right)$ : (1) 330, (2) 360, (3) 390, (4) 420, (5) 450", "Figure S6. FTIR spectra of the polar aromatics from the liquid product obtained to the temperature $\left({ }^{\circ} \mathrm{C}\right)$ : (1) 330, (2) 360, (3) 390, (4) 420, (5) 450", "Figure S7. GC-MS analysis of the liquid product obtained through asphaltenes pyrolysis at $390^{\circ} \mathrm{C}^{\prime}$, "Figure S8: Infrared spectrum of the gases from the pyrolysis of the asphaltenes", "Figure S9. H/C ratio of the reacted asphaltenes against the pyrolysis temperature", and "Table S1: Areas of the absorption bands of infrared spectra of the pyrolyzed asphaltenes".

Author Contributions: Conceptualization, N.A. and A.G.-C.; methodology, N.A. and A.G.-C.; validation, N.A., A.G.-C., and M.P.; formal analysis, N.A. and A.G.-C.; investigation, A.G.-C.; resources, N.A.; data curation, N.A. and A.G.-C.; writing-original draft preparation, A.G.-C.; writing-review and editing, N.A., A.G.-C., and M.P.; visualization, N.A., A.G.-C., and M.P.; supervision, N.A. and M.P.; project administration, N.A.; funding acquisition, N.A. All authors have read and agreed to the published version of the manuscript.

Funding: Authors thanks the Universidad del Valle for funding this research (Project No. 0130).

Conflicts of Interest: The authors declare no conflict of interest.

\section{References}

1. Liu, Y.J.; Li, Z.F. Structural characterisation of asphaltenes during residue hydrotreatment with light cycle oil as an additive. J. Chem. 2015, 2015, 580950. [CrossRef]

2. Mullins, O.C.; Sabbah, H.; Pomerantz, A.E.; Andrews, A.B.; Ruiz-morales, Y.; Mostow, F.; Mcfarlane, R.; Goual, L.; Lepkowicz, R.; Cooper, T.; et al. Advances in Asphaltene Science and the Yen-Mullins Model. Energy Fuels 2012, 26, 3986-4003. [CrossRef]

3. Xu, Q.; Zhang, Z.; Zhang, S.; Wang, F.; Yan, Y. Molecular Structure Models of Asphaltene in Crude and Upgraded Bio-Oil. Chem. Eng. Technol. 2014, 37, 1198-1204. [CrossRef] 
4. Shutkova, S.A.; Dolomatov, M.Y.; Dezortsev, S.V. Structural and Chemical Characteristics of Model Molecular Fragments of Petroleum Asphaltenes. Pet. Chem. 2012, 52, 267-271. [CrossRef]

5. Mullins, O.C. The Modified Yen Model. Energy Fuels 2010, 24, 2179-2207. [CrossRef]

6. Yen, T.F.; Chilingarian, G.V. Asphaltenes and Asphalts, 2; Elsevier: Amsterdam, The Netherlands, $2000 ;$ p. 64.

7. Zuo, P.; Qu, S.; Shen, W. Asphaltenes: Separations, structural analysis and applications. J. Energy Chem. 2019, 34, 186-207. [CrossRef]

8. Li, D.D.; Greenfield, M.L. High Internal Energies of Proposed Asphaltene Structures. Energy Fuels 2011, 25, 3698-3705. [CrossRef]

9. Chacón-Patiño, M.L.; Rowland, S.M.; Rodgers, R.P. Advances in Asphaltene Petroleomics. Part 3. Dominance of Island or Archipelago Structural Motif Is Sample Dependent. Energy Fuels 2018, 32, 9106-9120. [CrossRef]

10. Díaz-Sánchez, H.; Rojas-Trigos, J.B.; Leyva, C.; Trejo-Zárraga, F. An approach for determination of asphaltene crystallite by X-ray diffraction analysis: A case of study. Pet. Sci. Technol. 2017, 35, 1415-1420. [CrossRef]

11. Hemmati-Sarapardeh, A.; Ameli, F.; Ahmadi, M.; Dabir, B.; Mohammadi, A.H.; Esfahanizadeh, L. Effect of asphaltene structure on its aggregation behavior in toluene-normal alkane mixtures. J. Mol. Struct. 2020, 1220, 1-10. [CrossRef]

12. Fergoug, T.; Bouhadda, Y. Determination of Hassi Messaoud Asphaltene Aromatic Structure from ${ }^{1} \mathrm{H} \&{ }^{13} \mathrm{C}$ NMR Analysis. Fuel 2014, 115, 521-526. [CrossRef]

13. Speight, J.G. The Chemistry and Technology of Petroleum, 5th ed.; CRC Press: Boca Raton, FL, USA, 2014; pp. 299-302, 334-339.

14. Morgan, T.J.; Alvarez-Rodriguez, P.; George, A.; Herod, A.A.; Kandiyoti, R. Characterization of Maya Crude Oil Maltenes and Asphaltenes in Terms of Structural Parameters Calculated from Nuclear Magnetic Resonance (NMR) Spectroscopy and Laser Desorption-Mass Spectroscopy (LD-MS). Energy Fuels 2010, 24, 3977-3989. [CrossRef]

15. Dickinson, E.M. Structural Comparison of Petroleum Fractions Using Proton and ${ }^{13}$ C n.m.r. Spectroscopy. Fuel 1980, 59, 290-294. [CrossRef]

16. Speight, J.G. A Structural Investigation of the Constituents of Athabasca Bitumen by Proton Magnetic Resonance Spectroscopy. Fuel 1970, 49, 76-90. [CrossRef]

17. Ancheyta, J.; Centeno, G.; Trejo, F.; Speight, J.G. Asphaltene Characterization as Function of Time On-Stream during Hydroprocessing of Maya Crude. Catal. Today 2005, 109, 162-166. [CrossRef]

18. Savage, P.E.; Klein, M.T.; Kukes, S.G. Asphaltene Reaction Pathways. 1. Thermolysis. Ind. Eng. Chem. Process Des. Dev. 1985, 24, 1169-1174. [CrossRef]

19. Ruiz-morales, Y. Molecular Orbital Calculations and Optical Transitions of PAHs and Asphaltenes. In Asphaltenes, Heavy Oils, and Petroleomics; Mullins, O.C., Sheu, E.Y., Hammami, A., Marshall, A.G., Eds.; Springer: New York, NY, USA, 2007; pp. 95-137. [CrossRef]

20. Acevedo, S.; Escobar, G.; Ranaudo, M.A.; Rizzo, A. Molecular Weight Properties of Asphaltenes Calculated from GPC Data for Octylated Asphaltenes. Fuel 1998, 77, 853-858. [CrossRef]

21. Yasar, M.; Akmaz, S.; Ali Gurkaynak, M. Investigation of glass transition temperatures of Turkish asphaltenes. Fuel 2007, 86, 1737-1748. [CrossRef]

22. Liu, Y.; Hodek, W.; Heek, K.H. Characterization of tar, char and gas from pyrolysis of coal asphaltenes. Fuel 1998, 77, 1099-1105. [CrossRef]

23. Pramana, A.; Rachmat, S.; Abdassah, D.; Abdullah, M. A Study of Asphalttene Content of Indonesian. Heavy Oil 2012, 6, 64-73. [CrossRef]

24. Morantes, L.R.; Percebom, A.M.; Mejía-Ospino, E. On the Molecular Basis of Aggregation and Stability of Colombian Asphaltenes and Their Subfractions. Fuel 2019, 241, 542-549. [CrossRef]

25. AlHumaidan, F.S.; Hauser, A.; Rana, M.S.; Lababidi, H.M.S.; Behbehani, M. Changes in Asphaltene Structure during Thermal Cracking of Residual Oils: XRD Study. Fuel 2015, 150, 558-564. [CrossRef]

26. Liao, Z.; Zhao, J.; Creux, P.; Yang, C. Discussion on the Structural Features of Asphaltene Molecules. Energy Fuels 2009, 23, 6272-6274. [CrossRef]

27. Mullins, O.; Sheu, E. Structures and Dynamics of Asphaltenes; Springer: New York, NY, USA, 1999; pp. 87-89.

28. Bouhadda, Y.; Florian, P.; Bendedouch, D.; Fergoug, T.; Bormann, D. Determination of Algerian Hassi-Messaoud Asphaltene Aromaticity with Different Solid-State NMR Sequences. Fuel 2010, 89, 522-526. [CrossRef] 
29. Sjöblom, J.; Simon, S.; Xu, Z. Model Molecules Mimicking Asphaltenes. Adv. Colloid Interface Sci. 2015, 218, 1-16. [CrossRef]

30. Zhao, Y.; Wei, F.; Yu, Y. Effects of Reaction Time and Temperature on Carbonization in Asphaltene Pyrolysis. J. Pet. Sci. Eng. 2010, 74, 20-25. [CrossRef]

31. Gray, M.R.; McCaffrey, W.C. Role of Chain Reactions and Olefin Formation in Cracking, Hydroconversion, and Coking of Petroleum and Bitumen Fractions. Energy Fuels 2002, 16, 756-766. [CrossRef]

32. Akmaz, S.; Gurkaynak, M.A.; Yasar, M. The Effect of Temperature on the Molecular Structure of Raman Asphaltenes during Pyrolysis. J. Anal. Appl. Pyrolysis 2012, 96, 139-145. [CrossRef]

33. Alshareef, A.H.; Scherer, A.; Tan, X.; Azyat, K.; Stryker, J.M.; Tykwinski, R.R.; Gray, M.R. Effect of Chemical Structure on the Cracking and Coking of Archipelago Model Compounds Representative of Asphaltenes. Energy Fuels 2012, 26, 1828-1843. [CrossRef]

34. Savage, P.E. Mechanisms and Kinetics Models for Hydrocarbon Pyrolysis. J. Anal. Appl. Pyrolysis 2000, 54, 109-126. [CrossRef]

35. Douda, J.; Llanos, M.E.; Alvarez, R.; Navarrete, J. Structure of Maya Asphaltene-Resin Complexes through the Analysis of Soxhlet Extracted Fractions. Energy Fuels 2004, 18, 736-742. [CrossRef]

36. Yasar, M.; Trauth, D.M.; Klein, M.T. Asphaltene and Resid Pyrolysis. 2. The Effect of Reaction Environment on Pathways and Selectivities. Energy Fuels 2001, 15, 504-509. [CrossRef]

37. Trauth, D.M.; Yasar, M.; Neurock, M.; Nigam, A.; Klein, M.T.; Kukes, S.G. Asphaltene and Resid Pyrolysis. Effect of Reaction Environment. Fuel Sci. Technol. Int. 1992, 10, 1161-1179. [CrossRef]

38. Grin'ko, A.A.; Min, R.S.; Sagachenko, T.A.; Golovko, A.K. Aromatic Sulfur-Containing Structural Units of Resins and Asphaltenes in Heavy Hydrocarbon Feedstock. Pet. Chem. 2012, 52, 221-227. [CrossRef]

Publisher's Note: MDPI stays neutral with regard to jurisdictional claims in published maps and institutional affiliations. 